Revista lus et Praxis, Año 16, № 2, 2010, pp. 57 - 88

ISSN 0717 - 2877

Universidad de Talca - Facultad de Ciencias Jurídicas y Sociales

"Intereses y derechos en colisión sobre la identidad del progenitor biológico:

Los supuestos de la madre soltera y del donante de gametos"

Hernán Corral Talciani

\title{
INTERESES Y DERECHOS EN COLISIÓN SOBRE LA IDENTIDAD DEL PROGENITOR BIOLÓGICO: LOS SUPUESTOS DE LA MADRE SOLTERA Y DEL DONANTE DE GAMETOS*
}

\author{
INTERESTS AND RIGHTS IN CONFLICT ABOUT BIOLOGICAL PARENT'S IDENTITY: \\ THE UNMARRIED MOTHER AND SPERM DONOR'S CASES
}

Hernán Corral TalCiani**

\begin{abstract}
RESUMEN
A partir de un trabajo anterior del profesor español Ramón Durán, publicado en esta misma Revista, se analizan dos casos en los que se enfrentan derechos e intereses entre progenitores e hijos. En los dos casos el problema se presenta ante el reconocimiento y tutela de un derecho del hijo a conocer la identidad de sus progenitores, y las pretensiones de limitar ese derecho para garantizar el anonimato de ciertos progenitores, como la madre soltera que pretende así evitar las cargas de la maternidad sin atentar contra la vida y salud del hijo y el tercero aportante de esperma que desea que su intervención en la técnica de reproducción asistida no le ocasione responsabilidades ni situaciones incómodas frente a los hijos que se han concebido gracias a sus gametos. Se postula que deben distinguirse tres conceptos que pueden jugar a favor de la preferencia del interés del hijo: el principio de verdad biológica, el principio del interés superior del niño o favor filii y el derecho a la identidad. El trabajo proporciona argumentos para sostener la idea de que, al menos en el contexto jurídico y sociocultural chileno y latinoamericano, no se debe establecer ni el anonimato de la madre soltera ni la reserva del donante de gametos, y

se manifiesta favorable a propiciar una interpretación de los textos normativos que hagan primar el derecho del hijo a conocer la identidad de sus progenitores en ambos supuestos.
\end{abstract}

ABSTRACT

In light of a previous work by profesor Ramón Durán, from Spain, published in this same magazine, two cases will be analyzed in which the rights and interests of biological parents and offspring collide. In both cases, the problem arises from the recognition and protection of the right of a child to know the identity of his biological

\footnotetext{
* Este trabajo ha sido elaborado en el marco del Proyecto FONDECYT No 1070077/2007, "Los conflictos de intereses en las relaciones paterno-filiales", en la convocatoria "Incentivo a la Cooperación Internacional", en que participó el Catedrático de Derecho Civil de la Universidad de Oviedo, España, Dr. Ramón Durán Rivacoba. Trabajo recibido el 26 de abril y aprobado el 3 de junio de 2010.

** Doctor en Derecho por la Universidad de Navarra, España; Profesor titular de Derecho Civil, Universidad de los Andes. Correo electrónico: hcorral@uandes.cl.
} 
parents, and the attempts to limit that right by guaranteeing the anonymity of certain biological parents, such as the unmarried mother who by those means seeks to avoid the burdens of motherhood without endangering the life and health of the child and the third party sperm donor who desires that his participation in the reproductive procedure won't burden him with responsabilities or uncomfortable situations regarding the offspring that have been conceived thanks to his gametes. It is herein raised that three concepts must be made patent which can favor the prevalence of the interests of the child: the principle of biological truth, the principle of the superior interest of the child or favor filii and the right to identity. This work brings forward arguments to sustain the idea that, at least in the chilean and latinamerican legal and sociocultural context, neither the anonimity of the single mother nor that of the sperm donor must be established, and favors proposing an interpretation of the legal texts which give precedence to the right of the child to know the identity of his biological parents in both cases.

Palabras Clave

Filiación, Derecho a la Identidad, Derecho a la Privacidad

KEY WORDS

Filiation Laws, Right to Know Own Biological Identity, Privacy

\section{Objeto del Estudio}

Este trabajo pretende ser un contrapunto al artículo del catedrático español Ramón Durán Rivacoba que se publicó en el número anterior de esta misma Revista sobre las colisiones de intereses y derechos entre progenitores (que desean que su identidad sea reservada) e hijos (que aspiran a conocer de dónde procede su vida) que se plantean en el contemporáneo Derecho de la Filiación.

El profesor Durán ha tomado como base dos sentencias de altos tribunales españoles que, con poco espacio de tiempo, tuvieron que lidiar con este conflicto y llegaron a conclusiones diversas sobre los intereses y derechos que deben ser tutelados con prioridad: si la autonomía y vida privada del progenitor o el derecho a la identidad y a la verdad biológica del hijo. Uno de ellos se planteó en España en relación con las normas positivas que determinan que la madre no casada tiene derecho a no reconocer al hijo y a que se mantenga el anonimato de su identidad; el otro dice relación con las técnicas de reproducción asistida en que han intervenido donantes de gametos, en particular, de espermios, caso en el cual la ley especial que existe en España ha previsto también el derecho del donante a mantener reservada su identidad. Como se ve, en ambas ocasiones las normas positivas han dado prioridad al anonimato, restringiendo así el derecho a la identidad el hijo y el principio de la verdad biológica de la filiación. Ambas previsiones normativas fueron impugnadas como contrarias a la Constitución española, y aquí es donde se produce la divergencia: el Tribunal Supremo, por sentencia de 21 de septiembre de 1999, determinó que la reserva de la mater- 
nidad de la madre soltera era inconstitucional y que debía preferirse el interés del hijo a conocer a su progenitora; en cambio, en sentido justamente inverso, el Tribunal Constitucional, por sentencia de 17 de junio de 1999, rechazó la inconstitucionalidad planteada sobre la ley de técnicas de reproducción humana asistida y entendió que el anonimato del progenitor biológico, donante de semen, no era contrario a la Constitución y prevalecía por sobre el derecho a la identidad y a la verdad biológica del hijo.

El estudio del profesor Durán confronta ambas decisiones, además del caso "Odièvre" resuelto por la Corte Europea de Derechos Humanos que resolvió que la normativa existente en Francia protegiendo el anonimato de la madre soltera (parto bajo " $\mathrm{X}$ ") no era contraria a la Convención Europea de Derechos Humanos y, por tanto, era justificable que se restringiera el interés del hijo a conocer e identificar a su madre en estos casos (sentencia de 13 de febrero de 2003, No 2003/8).

El profesor Durán critica la dualidad de criterios de los tribunales españoles, pero coincide en que los dos casos planteados: anonimato de la madre y anonimato del padre-donante de gametos, deben tener soluciones diferentes, pero justamente las contrarias a los decididos judicialmente en España. Según su opinión, el anonimato de la madre no debe ser tachado de inconstitucional y se justifica, no sobre un interés de la madre, sino en interés justamente del hijo, que antes que conocer a sus padres, le interesa venir al mundo y no ser abortado o abandonado (como podría suceder si a la madre agobiada por el embarazo no cuenta con la posibilidad de darlo a luz y entregarlo a autoridades que puedan custodiarlo). Por el contrario, la reserva de identidad del progenitor biológico-donante de esperma le parece injustificada sobre la base del interés prioritario del hijo y la falta de consistencia de un supuesto derecho a la vida privada que se le concede al padre en desmedro del hijo, resucitando criterios que se estimaban superados con los avances obtenidos en pro de la libertad de investigación de la paternidad o maternidad.

Nuestro propósito consistirá en plantear estos mismos casos de colisión de intereses entre padres e hijos en el contexto latinoamericano, y más precisamente, en el chileno, para determinar si ellos pueden ser reproducidos del mismo modo que como está sucediendo en Europa, y particularmente en España. Como veremos, nuestra conclusión sólo en parte coincide con la del profesor Durán, pero pensamos que la diferencia de criterio se debe más a las circunstancias de contexto en que se plantean los casos que a una falta de convergencia en sus fundamentos jurídicos y éticos.

Iniciaremos el análisis con un examen dogmático abstracto de ciertos conceptos que conviene delimitar antes de entrar a utilizarlos en la solución de los problemas que se plantean en tema de anonimato e investigación de la paternidad o maternidad, y que son el principio de la verdad biológica, 
el interés superior del niño y el derecho a la identidad (II). Realizadas estas proposiciones nos ocupamos del problema de la reserva de la identidad de la madre soltera, partiendo por un análisis de la investigación de la maternidad y la verdad biológica de la filiación (III, 1), siguiendo por una revisión de la legislación chilena, en su evolución histórica y su estado actual (III, 2), así como de las previsiones normativas del Derecho de filiación latinoamericano (III, 3). Al observar que no existen normativas similares a la española y la francesa que otorguen a la madre no casada que da a luz el derecho a entregar al hijo bajo reserva de su identidad, se procede a examinar la cuestión de si sería conveniente introducir una fórmula de este tipo o si ello, en el contexto latinoamericano, debería desaconsejarse sobre la base de argumentos jurídicos (III, 4) e incluso sociológicos (III, 5). Finalmente, y siguiendo los presupuestos teóricos y la congruencia argumentativa con lo sostenido en el caso del anonimato de la madre, se examina la cuestión de la reserva de identidad del donante de semen en los supuestos de reproducción humana asistida y se efectúa una propuesta de lectura hermenéutica del art. 182 del Código Civil chileno, que posibilite una mejor conjugación de los intereses y derechos en juego (IV). Nuestra conclusión permitirá determinar que, si bien el principio de verdad biológica y el mismo derecho a la identidad del hijo no deben absolutizarse de manera de impedir toda restricción o limitación justificable, no hay buenas razones que permitan esa restricción o limitación para hacer prevalecer un derecho al anonimato de la madre soltera o del padre biológico donante de gametos $(\mathrm{V})$.

\section{Presupuestos teóricos: Verdad biológica, INTERÉS SUPERIOR DEL NIÑO Y DERECHO A LA IDENTIDAD}

\section{Principio de la verdad biológica y derecho a la identidad}

Es un hecho indiscutido que una de las características o paradigmas del Nuevo Derecho de la Filiación, cuyos modelos normativos comienzan a diseñarse y ponerse en vigor a partir de la segunda mitad del siglo XX, es la sustitución del principio de la verdad formal por el de la verdad biológica en el establecimiento jurídico de los lazos de filiación, paternidad y maternidad. Podría decirse que este principio y el de igualdad de derechos de los hijos, son los dos ejes sobre los que se han construido las reformas al modelo tradicional de regulación de la filiación, que procede de la codificación decimonónica.

El principio de la verdad biológica fue impulsado no sólo por cambios ideológicos y culturales, sino también -hay que reconocerlo- por los avances científicos que, por medio de test genéticos, hicieron posible la demostración probatoria tanto de la exclusión como de la inclusión de paternidad. Normalmente, no se trataba de averiguar quién era la madre de un niño, ya que en la maternidad el hecho del parto indica con facilidad la identidad de la progenitora 
(de allí el adagio mater semper certa est). Era la paternidad la que en muchas ocasiones se escabullía de la determinación jurídica. Las políticas legislativas trataban de evitar juicios que causaban escándalo social sin que hubiera maneras de determinar indubitablemente una verdad que pudiera justificar la discusión judicial. Por eso, las trabas por ejemplo para impugnar la filiación legítima y el otorgamiento al marido del derecho casi exclusivo de desconocer al hijo nacido respecto de la mujer que contrae nupcias, y las dificultades para reclamar la filiación incluso ilegítima o natural respecto de personas casadas. Las concepciones de que se podía comprobar la verdadera filiación y de que era un derecho del hijo conocer esa realidad abrieron este terreno erizado de cortapisas y restricciones, para dar lugar a la libertad de investigación de la paternidad, a lo que se sumó, aunque con menos relevancia práctica, la de la maternidad.

El principio de verdad biológica nace, por tanto, como un estándar normativo que va en beneficio del hijo que ha sido procreado, pero que va más allá, por cuanto se entiende al derecho del padre formal a destruir la filiación que no corresponde a la realidad biológica, y ello aunque vaya en contra del interés del hijo, que podrá quedar sin padre legal. También se amplía al interés del padre biológico para impugnar la paternidad formal en beneficio no sólo del hijo sino del mismo progenitor demandante. Pareciera, en consecuencia, que el principio de verdad biológica es valorado no sólo como una expresión del principio de protección al hijo (favor filii) sino como una pauta normativa que interesa a toda la regulación de la filiación, con todos sus involucrados: padres e hijos. En suma, el principio de verdad biológica es considerado un elemento que favorece una mejor organización y desarrollo de los lazos familiares que se generan por la filiación. En el fondo, la ley asume que la verdad, incluso aunque inesperada y a veces dura, es mejor que la falsedad y la mentira en la regulación de la familia: verita libera nos (la verdad nos hará libres).

Con lo anterior no pretendemos negar que en una gran parte de los casos el principio de verdad biológica tiene por beneficiario al hijo. Es a éste a quien le interesa conocer quiénes son sus verdaderos progenitores y ello no sólo por la necesidad de reclamar de éstos los deberes de afecto y ayuda material conectados a la paternidad o maternidad, sino también porque él puede reconocerse y determinarse como individuo humano singular y único. La pregunta ¿de dónde vengo?, ¿cuál es mi historia?, se presentan como fundamentales para la construcción de una personalidad psicológicamente sana. De allí que rápidamente se haya conectado el principio de verdad biológica, como un derecho del hijo, y más específicamente, del hijo a construir su propia identidad. El principio asume entonces la característica de un derecho humano, derecho fundamental o derecho de la personalidad tutelado por instrumentos jurídicos de alto rango: tratados internacionales y constituciones. 
El Pacto Internacional de Derechos Políticos y Civiles declara que "todo niño será inscrito inmediatamente después de su nacimiento y deberá tener un nombre" y que "todo niño tiene derecho a adquirir una nacionalidad" (art. $24 \mathrm{~N}^{\circ}$ s. 2 y 3). La Convención Americana sobre Derechos Humanos (Pacto de San José de Costa Rica) dispone que "toda persona tiene derecho a un nombre propio y a los apellidos de sus padres o al de uno de ellos. La ley reglamentará la forma de asegurar este derecho para todos, mediante nombres supuestos, si fuere necesario" (art. 18). De aquí la Convención de Derechos del Niño avanza más hacia el derecho a conocer el origen biológico y dispone que "El niño será inscrito inmediatamente después de su nacimiento y tendrá derecho desde que nace a un nombre, a adquirir una nacionalidad y, en la medida de lo posible, a conocer a sus padres y a ser cuidado por ellos" (art. $7 \mathrm{~N}^{\circ} 1$ ). Agrega además que "Los Estados Partes se comprometen a respetar el derecho del niño a preservar su identidad, incluidos la nacionalidad, el nombre y las relaciones familiares de conformidad con la ley y sin injerencias ilícitas" (art. $8 \mathrm{~N}^{\circ} 1$ ). El tratado sigue diciendo que "cuando un niño sea privado ilegalmente de alguno de los elementos de su identidad o de todos ellos, los Estados Partes deberán prestar la asistencia y protección apropiadas con miras a restablecer rápidamente su identidad" (art. $8 \mathrm{~N}^{\circ} 2$ ).

En el ámbito europeo el Tribunal de Estrasburgo ha declarado que el derecho a la identidad forma parte del núcleo duro del derecho al respeto a la vida privada sancionado en el art. 8 de la Convención Europea de los Derechos Humanos (Pretty c. Royaume-Uni n. 2346/02, § 61, CEDH 2002-III; Bensaid c Royaume-Uni No 44599/98, § 47, CHDH 2001-I), y que en él se contiene el derecho al acceso al expediente confidencial de un niño que ha sido colocado en la asistencia pública desde su temprana infancia (Gaskin c. Royaume-Uni, 7 de julio de 1989, serie $A N^{\circ} 160$ ) o a obtener información necesaria para el descubrimiento de la verdad concerniente a un aspecto importante de su identidad personal como lo es la identidad de sus progenitores (Mikulic C. Coratie, № 53176/99, §§ 54 y 64, CEDH 2002-I). La Recomendación 1443, de 26 de enero de 2000, de la Asamblea Parlamentaria del Consejo de Europa, "Para un respeto de los derechos del niño en la adopción internacional", contiene una invitación a los Estados para "asegurar el derecho del niño adoptado de conocer sus orígenes a más tardar a su mayoría de edad y a eliminar de sus legislaciones nacionales toda disposición en contrario". La Convención de La Haya de 29 de mayo de 1993 sobre protección de los niños y cooperación en materia de adopción internacional, dispone que las autoridades competentes del Estado contratante velarán por conservar las informaciones sobre los orígenes del niño, especialmente las relativas a la identidad de su madre y de su padre, así como los datos sobre el pasado médico del hijo y de su familia. Se asegura así el acceso del hijo o de su representante a esta 
información con los consejos apropiados, en la medida permitida por la ley de su Estado (art. 30).

En todas estas normas e interpretaciones jurisprudenciales puede apreciarse que se reconoce un derecho a la identidad, que parte por el nombre pero se desarrolla hasta las relaciones familiares y, concretamente, al derecho del niño a conocer la identidad de sus padres o progenitores biológicos, en la medida de lo posible. También surge un deber para el Estado de respetar esta identidad y de prestar asistencia y protección apropiadas para restablecer dicha identidad en caso de que sea afectada de algún modo. Entendemos que dentro de esas medidas está el acceso a la justicia y la posibilidad de determinar la verdadera identidad de los progenitores ${ }^{1}$.

Nuestro Tribunal Constitucional ha tenido oportunidad de pronunciarse sobre la vigencia del derecho a la identidad en nuestro ordenamiento y ha sustentado una posición favorable basada en su vinculación con el concepto de dignidad humana como en su consagración en tratados internacionales de derechos humanos. En sentencia inaplicabilidad por inconstitucionalidad de 29 de septiembre de 2009, sostiene que "debe reconocerse, en efecto, que los diversos instrumentos internacionales, ratificados por Chile y vigentes, que cita el juez requirente en apoyo de su argumentación [los mismos que se mencionan más arriba], consagran el derecho a la identidad personal generando, por ende, la obligación de los órganos del Estado de respetarlos y promoverlos, en los términos aludidos en el inciso segundo del artículo $5^{\circ}$ de la Carta Fundamental. La afirmación precedente se concilia perfectamente con el criterio sostenido por esta Magistratura en el sentido de que el derecho a la identidad personal está estrechamente ligado a la dignidad humana, en cuanto valor que, a partir de su consagración en el artículo $1^{\circ}$, inciso primero, de la Ley Suprema, constituye la piedra angular de todos los derechos fundamentales que la Ley Suprema consagra. Asimismo, que aun cuando la Constitución chilena no reconozca, en su texto, el derecho a la identidad, ello no puede constituir un obstáculo para que el juez constitucional le brinde adecuada protección, precisamente por su estrecha vinculación con la dignidad humana y porque se encuentra protegido expresamente en diversos tratados internacionales ratificados por Chile y vigentes en nuestro país" (Sentencia de 21 de septiembre de 2009, Rol No 1340-9)².

\footnotetext{
${ }^{1}$ Sobre las implicancias del derecho a la identidad respecto del niño, puede verse a Lloveras, Nora, "La identidad personal: lo dinámico y lo estático en los derechos del niño", Derecho de Familia. Revista interdisciplinaria de doctrina y jurisprudencia 13, 1998, pp. 65-84.

${ }^{2}$ Ya con anterioridad, el Tribunal Constitucional había relacionado el derecho a la identidad con el concepto de dignidad humana. Así había señalado "El derecho a la identidad personal comprende -en un sentido amplio- la posibilidad de que todo ser humano sea uno mismo y no otro y, en un sentido restringido, el derecho de la persona a ser inscrita inmediatamente después de su nacimiento, a tener un nombre desde que nace $y$, en la medida de lo posible, a conocer a sus padres y a ser cuidado por
} 


\section{Interés superior del niño y derecho a la identidad}

Pareciera que no hay desacuerdo en que tanto en las decisiones legislativas, administrativas como judiciales en las que se vean implicados menores de edad o niños ${ }^{3}$, en los términos de la Convención de Derechos del Niño, el interés de éste debe ser considerado con particular relevancia. La Convención de Nueva York lo expresa claramente: "En todas las medidas concernientes a los niños que tomen las instituciones públicas o privadas de bienestar social, los tribunales, las autoridades administrativas o los órganos legislativos, una consideración primordial a que se atenderá será el interés superior del niño". No discutiremos aquí en qué consiste específicamente este "interés superior" del menor, pero parece indisputable que el mandato imperativo de la Convención contiene al menos dos partes: primero la de identificar cuál sea el interés superior del niño, y segundo resolver o adoptar las medidas ateniendo a él de manera primordial, es decir, de alguna forma, privilegiada.

El estándar normativo del interés superior del niño cuando se trata de conflictos de intereses entre padres o ascendientes y un menor que es hijo, asume la denominación usual de favor filii, o interés superior del hijo. La reforma al régimen de filiación chileno operada por la Ley № 19.585 lo aplicó expresamente en varias normas, que reflejan la influencia de la Convención de Derechos del Niño en materia de relaciones paterno-filiales. Se señala así que "La preocupación fundamental de los padres es el interés superior del hijo, para lo cual procurarán su mayor realización espiritual y material posible, y lo guiarán en el ejercicio de los derechos esenciales que emanan de la naturaleza humana de modo conforme a la evolución de sus facultades" (art. 222 inc. $2^{\circ}$ del Código Civil). A ello se agrega que en los procesos relativos a los derechos de los padres sobre los hijos, "para adoptar sus resoluciones el juez atenderá como consideración primordial, al interés superior del hijo, y tendrá debidamente en cuenta sus opiniones, en función de su edad y madurez" (art. 242 inc. $2^{\circ}$ del Código Civil). Específicamente en materia de cuidado personal, la ley dispone que si bien a la madre toca el cuidado de los hijos, "en todo caso, cuando el interés del hijo lo haga indispensable, sea por maltrato, descuido u otra causa calificada, el juez podrá entregar su cuidado personal al otro de los padres" (art. 225 inc. $3^{\circ}$ del Código Civil). Incluso en una materia tan ligada a la investigación de la paternidad el Código Civil vuelve a poner al juez ante

ellos. Desde este punto de vista existe una estrecha vinculación entre el derecho a la identidad personal y la dignidad humana -piedra angular de todo el edificio de los derechos fundamentales- pues ésta sólo se afirma cuando la persona goza de la seguridad de conocer su origen y, sobre esa base, puede aspirar a ser reconocida como tal dentro de la sociedad" (Sentencia de 13 de mayo de 2008, Rol № 834).

${ }^{3}$ Según la Convención se entiende por niño todo ser humano menor de dieciocho años de edad, salvo que, en virtud de la ley que le sea aplicable, haya alcanzado antes la mayoría de edad. 
la necesidad de distinguir cuál sea el mejor interés del hijo, por sobre los intereses de sus padres sociales o biológicos. De esta forma, se dispone que si en un juicio de filiación aparece una contradicción entre el padre que indica la posesión notoria y lo que se concluye por los tests biológicos, el juez debe dar preferencia a la primera y no a la prueba biológica: "sin embargo -señala la norma-, si hubiese graves razones que demuestren la inconveniencia para el hijo de aplicar la regla anterior, prevalecerán las pruebas de carácter biológico" (art. 201 inc. $2^{\circ}$ ).

A este estándar normativo que debe aplicarse a las contiendas en las que confluyen intereses diversos provenientes de los padres o de alguno de ellos y los hijos, hay que agregar ahora el derecho a la identidad, en su dimensión dinámica de conocer la historia personal y concretamente, dentro de lo posible, quiénes han sido los progenitores biológicos. Nos parece que es bueno no confundir ambos figuras jurídicas: el favor filii o interés superior del hijo y el derecho a la identidad que le puede asistir. En primer lugar, porque el derecho a la identidad, si se le reconoce como tal, es más que un simple y mero interés, y tiene la consistencia y garantía de un derecho fundamental de las personas o, en términos civiles, de un derecho de la personalidad. En segundo término, porque el derecho a la identidad corresponde a toda persona y no sólo a los menores de edad o niños, ni tampoco a los que invocan su estado filiativo. Debe recordarse que la noción de derecho a la identidad ha sido forjada para proteger primariamente la "verdad" de la persona proyectada en su vida social de distorsiones producidas por la libertad de información y de ahí se ha ido ampliando a otros ámbitos ${ }^{4}$.

La distinción conceptual entre favor filii o interés superior del niño y derecho a la identidad no empece a que ambos puedan resultar convocados en una determinada situación o conflicto, y así sucede, pensamos, cuando se trata del

\footnotetext{
${ }^{4}$ Sobre el particular, puede verse el estudio de Fernández Sessarego, Carlos, Derecho a la identidad personal, Astrea, Buenos Aires, 1992, muy tributario de la doctrina y jurisprudencia italiana. Según el autor, "la identidad personal se presenta, por todo lo expuesto, como un preponderante interés existencial que merece tutela jurídica. Es una situación jurídica subjetiva por la cual el sujeto tiene el derecho a ser representado fielmente en su proyección social. Tiene derecho a que se le conozca y defina en su 'verdad personal', tal cual es, sin alteraciones, desfiguraciones, falseamientos, distorsiones o desnaturalizaciones de sus atributos, tanto estáticos como dinámicos, que lo distinguen de los demás en cuanto lo hacen ser 'él mismo' y no 'otro'. El derecho a la identidad supone la exigencia del respeto de la propia biografía, con sus luces y sus sombras, con lo que exalta y con lo que degrada. Ante el derecho de la persona se yergue el deber de los demás de respetar la 'verdad' que cada cual proyecta, de modo objetivo, en su vida de relación social. Tratándose de una situación jurídica subjetiva hallamos también que frente al derecho del sujeto, aparece a su vez, su propio deber de ser auténtico en las manifestaciones externas de su personalidad, de que ella se exprese tal cual es. No puede perderse de vista que la identidad es la proyección social de una 'verdad personal', de una manera individual de ser humano. Es esta verdad la que configura el interés existencial digno de tutela jurídica" (pp. 114-115).
} 
problema del conocimiento de la verdad biológica de la procreación. Lógicamente puede invocarse en su ayuda y auxilio el favor filii o interés superior del hijo, puesto que es indiscutible que es conveniente y necesario para su desarrollo el que le sea posible conocer la identidad de sus progenitores. Pero, además, ese interés será reforzado (o sustituido cuando el menor haya dejado de ser tal y esté en la adultez), por la necesidad de respetar su derecho a la identidad personal, a través del cual él puede exigir que el Estado y el ordenamiento jurídico le haga posible determinar cuáles son las raíces de su progenie.

A pesar de esta confluencia y relativa confusión en el caso concreto de la investigación de la paternidad o maternidad, resulta importante para la resolución de los conflictos el apreciar que deben ser ponderados tanto un interés (el del niño o hijo) como un derecho fundamental, el derecho a la identidad (ahora de toda persona cualquiera sea su edad).

Hechas estas precisiones podemos abordar las cuestiones sobre anonimato de la madre y del progenitor donante de gametos. Comenzamos por la reserva de identidad de la madre.

\section{Sobre EL POSIBLE ANONIMATO DE LA MADRE}

\section{Maternidad y principio de verdad biológica}

Como ya queda dicho, el principio de verdad biológica nace más como una reivindicación del derecho a investigar la paternidad que como una necesidad de descubrir quién es la verdadera madre de un niño. Ya dimos uno de los motivos para que ello sucediera así: la naturaleza biológica de la reproducción impide, o hace más dificultoso, que se oculte la identidad de la madre. Añadamos a esta razón biológica una de carácter antropológico-cultural: la madre suele ser más acogedora del niño que llega y es más difícil que esté interesada en desconocerlo y abandonarlo (por eso es que los casos en los que esto sucede despierte tan fuerte reacciones en contra por parte de la opinión pública).

No obstante, el temor a las sanciones sociales o a los gravámenes onerosos de la maternidad y crianza de un hijo cuya concepción no fue deseada pueden inducir a la madre a abandonar al hijo o, lo que es peor, a privarlo de la vida, ya sea antes del nacimiento (por medio del aborto) o después de él (por el infanticidio).

Por eso es que algunas legislaciones europeas prevén la posibilidad de que la madre se ampare en el anonimato al momento del nacimiento e inscripción del hijo, y que éste sea entregado a una entidad de amparo de menores o sea adoptado por otras personas. Esta fórmula pareciera incentivar a la madre a que no mate o no abandone a su suerte a su hijo, a cambio de una total protección del secreto de su identidad, frente a posibles reclamaciones de investigación de la maternidad que el hijo pudiera en un futuro interponer. 
Por cierto, esta medida legislativa vulnera el principio de verdad biológica ya que impide que el hijo que ha sido objeto de ella pueda conocer quién fue su progenitora. Lo priva de conocer la verdadera maternidad. Pero también por una lógica derivación le impedirá, en la mayor parte de los casos, conocer quién fue su padre. No contando con el testimonio de la madre es prácticamente imposible identificar al progenitor masculino. En suma, el hijo queda privado de conocer a sus padres. ¿Es esta vulneración del principio de verdad biológica justificada? ¿Es posible desconocer en este caso el derecho a la identidad asegurado por tratados internacionales como los citados?

Antes de responder esta pregunta, nos parece conveniente contextualizarla describiendo la evolución del Derecho Civil chileno en la materia, y además la forma en la que se asume la cuestión en la legislación latinoamericana. Pensamos que puede servir de contraste respecto del panorama que se observa en la legislación europea y que expone en su trabajo el profesor Durán.

\section{Determinación de la maternidad en la legislación chilena}

El Código Civil chileno en su texto original de 1855, redactado por Andrés Bello, siguió de cerca al Código Civil francés y restringió fuertemente la investigación de la paternidad. En cambio, fue mucho más liberal en lo concerniente a la investigación de la maternidad. Se observa que esta diferencia fue bien meditada por el codificador y que no llegó a ella sino después de dudar si no era más conveniente el planteamiento absolutamente restrictivo asumido por el Proyecto de Código Civil español de 1851, de Florencio García Goyena. Éste había dejado establecido en su proyecto una norma categórica en contra de la investigación no sólo de la paternidad sino de la maternidad: "Se prohíbe, en todo caso, la investigación de la paternidad y la maternidad de los hijos nacidos fuera del matrimonio" (art. 127).

Las razones que da García Goyena para establecer esta prohibición pesaron en Bello, pero finalmente no lo convencieron. Dejó escrito, sin embargo, en el Mensaje del Código que "Ni se ha vedado sino en raros casos la investigación de la maternidad por los medios ordinarios, aunque para igualar en esta parte al padre y a la madre no faltarían razones gravísimas que un ilustre jurisconsulto, el presidente de la comisión redactora del Código Civil español, ha hecho valer con mucha verdad, sensatez y filosofía".

En definitiva, el Código permitió la investigación de la maternidad, pero sólo como una forma de obtener alimentos para el hijo, al que calificó de ilegítimo. Para alcanzar la categoría de hijo natural debía tratarse de un hijo que no fuera el resultado de un "dañado ayuntamiento" (incesto, adulterio o sacrilegio) y que hubiera sido reconocido voluntaria y solemnemente por el padre o por la madre o por ambos (arts. 270-272). 
Para tener la calidad de hijo ilegítimo pero con derecho a alimentos, el Código distinguía entre el padre y la madre. Respecto de la paternidad, se permitía al hijo pedir que el supuesto padre fuera citado ante el juez para declarar bajo juramento y sólo si reconocía al hijo se establecía el vínculo filial para estos limitados efectos (art. 282). La ley morigeraba este rigor disponiendo que si, repetidas dos veces la citación, el demandado no comparecía pudiendo hacerlo, la paternidad se miraba como reconocida (art. 283). En definitiva, el hijo demandante no podía rendir prueba alguna de paternidad; sólo el reconocimiento - expreso o tácito por no concurrencia- estimulado por citación judicial podía servirle para determinar la paternidad. El Código clausuraba el sistema señalando que "No es admisible la indagación o presunción de paternidad que por otros medios que los expresados en los dos artículos anteriores" (art. 284).

Pero en el caso de la maternidad el juicio probatorio era permitido. Se señalaba primeramente que "El hijo ilegítimo tendrá derecho a que su madre le asista con los alimentos necesarios, si no pudiere obtenerlos del padre" (art. 288 inc. $1^{\circ}$ ). Para ello debía demandarla y en tal caso señalaba el Código: "si la demandada negare ser suyo el hijo, será admitido el demandante a probarlo con testimonios fehacientes que establezcan el hecho del parto, y la identidad del hijo" (art. 289 inc. $1^{\circ}$ ). Sólo se excluía como prueba la partida de nacimiento: "La partida de nacimiento o bautismo no servirá de prueba para establecer la maternidad" (art. 289 inc. $2^{\circ}$ ). La mayor restricción colocada por el Código a esta investigación era la imposibilidad de someter a este juicio a una mujer casada: "No podrá intentarse esta acción contra ninguna mujer casada" (art. 288 inc. $2^{\circ}$.

El art. 320 del Código parecía abrir la posibilidad de investigación de la paternidad y maternidad, al disponer en su inciso primero que "Ni prescripción ni fallo alguno, entre cualesquiera otras personas que se haya pronunciado, podrá oponerse a quien se presente como verdadero padre o madre del que pasa por hijo de otros, o como verdadero hijo del padre o madre que le desconoce". Pero la norma abierta era restringida en su inciso segundo, que rezaba: "Lo cual se entenderá sin perjuicio de lo dispuesto en los art. 284 y 288 inc. $2^{\circ \prime}$, es decir, las restricciones para investigar la paternidad o maternidad ilegítimas.

Respecto de la impugnación de la maternidad determinada el Código era mucho más abierto. Señalaba que "La maternidad, esto es, el hecho de ser una mujer la verdadera madre del hijo que pasa por suyo, podrá ser impugnada, probándose falso parto o suplantación del pretendido hijo al verdadero" (art. 293). Se daba la acción al marido de la supuesta madre y a la madre supuesta, a los verdaderos madre o madre legítimos, y a la verdadera madre, aunque ilegítima (para exigir alimentos al hijo). También se concedía la acción de manera amplia a toda otra persona a quien la maternidad putativa perjudique actualmente en sus derechos en la sucesión de los supuestos padre o madre (art. 295). 
Este diseño original comenzó a variar a comienzos del siglo XX por varias leyes que, sin alterar la estructura fundamental del sistema, comenzaron a otorgar más derechos a los hijos naturales, y abrieron la posibilidad de investigar la paternidad y ampliaron la facultad de investigar la maternidad ${ }^{5}$. La maternidad pudo ser comprobada en juicio, ya no sólo para efectos alimenticios, sino para que el hijo adquiriera la categoría de natural, con todos los derechos atribuidos a esa filiación, que también fueron incrementados.

La Ley № 19.585, de 1998, después de larga discusión, sustituyó completamente el modelo de regulación original del Código y estableció igualdad de derechos entre hijos de filiación matrimonial e hijos de filiación no matrimonial, suprimió el derecho de los hijos a sólo pedir alimentos a los supuestos padres, y estableció como principio informador el de la verdad biológica. El nuevo art. 195 del Código proclama solemnemente, en forma similar a la Constitución española, que "la ley posibilita la investigación de la paternidad o maternidad, en la forma y con los medios previstos en los artículos que siguen".

Pero, además, la ley estableció una nueva forma de determinación de la maternidad que antes, y sólo por la práctica, se aplicaba únicamente a la madre legítima ${ }^{6}$. Se trata de la determinación de la maternidad, sea matrimonial o no matrimonial, por el simple hecho del parto, y sin necesidad de reconocimiento

\footnotetext{
${ }^{5}$ En relación con la maternidad, la Ley № 5.579, de 2 de diciembre de 1935, mantuvo, aunque cambió de ubicación normativa, el precepto del antiguo art. 289, que pasó a integrar el № 3 del art. 280, como una de las formas de investigación de la filiación ilegítima. Pero además hizo aplicables a la maternidad otros casos de investigación que se redactaron de modo de comprender tanto la paternidad como la maternidad: así se aceptó dicha investigación si la madre reconoció al hijo por instrumento público o si contribuyó al mantenimiento del hijo (cfr. Somarriva, Manuel, Evolución del Código Civil chileno, Nascimento, Santiago, 1955, № 91, p. 164). Posteriormente, la Ley № 10.271, de 2 de abril de 1952, cambió la norma del № 3 del art. 280 al № 4 del art. 270, dándole la virtualidad de ser causa de investigación de la maternidad no ilegítima simplemente (con efectos limitados a los alimentos) sino natural. De esta manera se consideraba hijos naturales a "lo que hubieren obtenido declaración de maternidad fundada en la circunstancia precisa de haberse establecido, con testimonios fidedignos, el hecho del parto y la identidad del hijo". Dentro de los testimonios fidedignos era admitida la prueba testimonial (SOMARRIVA, Evolución, recién citado, n. 103, p. 182).

${ }^{6}$ La ley se preocupaba solamente de establecer la paternidad por medio de la presunción pater is est, pero la presunción se basaba en el establecimiento de la maternidad que resultaba de la inscripción en el Registro Civil. Así se señalaba que la prueba del parto se efectuaba por la partida de nacimiento y de ella se presumía la identidad para todo aquel que quisiera alterar la situación vigente. Somarriva, resumiendo la opinión común, escribe que "Esta última, que es la doctrina aceptada por todos los jurisconsultos, es, sin duda, la que ha seguido nuestro Código. En consecuencia, la identidad o no identidad deberá ser probada por el que trate de alterar la situación existente. Por lo tanto, si un hijo reclama su estado de hijo legítimo del cual no está en posesión, al exhibir la partida de nacimiento deberá acreditar la identidad por cualquier medio de prueba. Por el contrario, si el hijo, además de tener su partida de nacimiento, se encuentra en posesión del estado de hijo legítimo y alguien pretende discutírselo, a éste tocaría probar que la partida que aquél exhibe no es la suya" (SOMARRIVA, Manuel, La filiación. Estudio doctrinal y de legislación comparada, Imprenta "El esfuerzo", Santiago, 1931, p. 25).
} 
expreso o tácito de la madre. Según el nuevo art. 183, "la maternidad queda determinada legalmente por el parto, cuando el nacimiento y las identidades del hijo y de la mujer que lo ha dado a luz constan en las partidas del Registro Civil". En consonancia con esta disposición, se reformó el art. 31 de la Ley № 4.808, del Registro Civil, para establecer que el Oficial de Registro Civil debe dejar constancia en la partida de los nombres y apellidos de la madre, aunque no haya reconocimiento, "cuando la declaración del requirente coincida con el comprobante del médico que haya asistido al parto, en lo concerniente a las identidades del nacido y de la mujer que lo dio a luz" ${ }^{\prime \prime}$.

No se contempla posibilidad de que la mujer sea consultada, o que se oponga o deniegue esta forma de determinación. Si ella piensa que el hijo que fue inscrito bajo su nombre no es realmente de ella debe ejercer la acción de impugnación de la maternidad de acuerdo con los arts. 217 y siguientes, bas-

\footnotetext{
${ }^{7}$ Desde un comienzo el proyecto de ley que llegaría a ser la Ley № 19.585 introducía esta forma automática de determinación de la maternidad. El art. 183 del Código Civil reformado por este proyecto decía "La maternidad quedará establecida, aun sin mediar reconocimiento expreso, por la prueba del nacimiento y la identidad del nacido" (Mensaje Boletín № 1060-07, Cámara de Diputados sesión $25^{\text {a }}$ 10 de agosto de 1993, p. 2488; el Mensaje del Ejecutivo no menciona la razón de esta disposición). El Proyecto aprobado por la Cámara de Diputados reprodujo la norma sin cambios. En el Senado, la Comisión de Constitución, Legislación, Justicia y Reglamento, en su primer informe, coincidió con el fondo de la norma: "Este artículo pretende consagrar los elementos constitutivos de la maternidad que la doctrina ha extraído de los actuales artículos 271 № 4 y 293 [del Código Civil], en el sentido de que ella es un hecho cierto, observable físicamente, que está constituido por el parto y la identidad del nacido... De esta forma, a las dos vías actuales de determinación de la maternidad, cuales son el reconocimiento y la sentencia judicial, se agrega una modalidad que opera por el solo ministerio de la ley, cual es la que contempla la primera de las reglas señaladas". La Comisión hizo algunos cambios formales y de operatividad de la regla: cambió la palabra "establecida" por "determinada" y agregó un inciso segundo para aclarar que en los demás casos la maternidad se determina por reconocimiento o sentencia firme en juicio de filiación. Además, añadió una reforma a la Ley de Registro Civil para ordenar que el Oficial de Registro Civil debía dejar constancia del nombre de la madre cuando la declaración del requirente de la inscripción de nacimiento era coincidente con el comprobante del médico que haya asistido al parto en lo concerniente a las identidades de la madre y del hijo (Primer Informe de la Comisión de Constitución del Senado de 20 de noviembre de 1996, Diario de Sesiones Sesión $12^{a}$ de 3 de diciembre de 1996, p. 1616). La norma no tendría otras innovaciones hasta que el proyecto fuera definitivamente aprobado en 1998. En: http://www.leychile.cl/Navegar?idNorma=126 $366 \&$ buscar $=19585$ [visitado el 17/05/2010].

No aparece en los antecedentes de la reforma cuál fue el origen remoto del precepto. Pareciera que su fuente está en el Código Civil Portugués, modificado por el Decreto Ley No 496/77, de 25 de noviembre, que estableció que la filiación materna se determina por declaración de maternidad en la partida de nacimiento. Conjeturamos esto por el hecho de que el trabajo académico que precedió a la reforma de 1998 propiciando un régimen igualitario de la filiación, elaborado por las profesoras Leonor Etcheberry Court y Paulina Veloso Valenzuela, y que por primera vez, aunque no del todo clara, postula que la maternidad debía resultar del hecho del nacimiento, menciona expresamente, al tratar del Derecho comparado, este punto de la legislación portuguesa. Cfr. EtcheberRY, Leonor; Veloso, Paulina, "Proposiciones relativas a una nueva normativa en ciertas materias de filiación", en BARROS, Enrique (Coord.), Familia y personas, Editorial Jurídica de Chile, Santiago, 1991, pp. 19 y ss., esp. pp. 30-32.
} 
tante similares a los preceptos del Código original, es decir, se permite probar en juicio, incluyéndose los medios biológicos, que hubo falso parto o suplantación del pretendido hijo al verdadero.

Si la maternidad no se determina por el parto, la madre puede reconocer al hijo (salvo que tenga una maternidad distinta ya determinada, caso en el cual deberá impugnar ésta de modo judicial) o el hijo puede reclamar la verdadera maternidad mediante la acción de reclamación de la filiación, que es imprescriptible.

La única limitación es la establecida en el art. 182 respecto de los hijos nacidos como resultado de la aplicación de una técnica de reproducción artificial o asistida. Esta norma señala que serán padre y madre de este hijo el hombre y la mujer que se "sometieron" a las técnicas y que "no podrá impugnarse la filiación determinada de acuerdo a la regla precedente, ni reclamarse una distinta" (art. 182 inc. $\left.2^{\circ}\right)^{8}$.

La determinación de la maternidad por el parto ha sido una de las innovaciones más importantes, aunque menos destacada, de la reforma de 1998. Ella beneficia más que nada a los hijos de filiación no matrimonial, que en la mayor parte de las veces, gracias a esta reforma, contarán con madre determinada sin necesidad de esperar el reconocimiento, ni siquiera tácito de la mujer que lo dio a luz. Para la filiación matrimonial la novedad es más formal que real, ya que, aunque la ley no lo señalaba expresamente, la práctica, avalada por la doctrina, permitían deducir la maternidad de la sola declaración del marido que inscribía al hijo como tal en el Registro Civil9 . La doctrina ha recibido con beneplácito

\footnotetext{
${ }^{8}$ A nuestro juicio, sin embargo, la norma no se aplica al hijo, el que podría investigar la identidad de los progenitores biológicos, según exponemos más abajo.

${ }^{9}$ Los autores anteriores a la reforma señalaban que la filiación legítima se construía sobre la base de la prueba de la maternidad que operaba por la inscripción de nacimiento. SOMARrIva, Manuel, Derecho de Familia, Nascimento, Santiago, 1963, № 417, p. 393, indicaba respecto de la maternidad como elemento de la filiación legítima: "Es el hecho que una mujer haya tenido un parto y que el hijo que pasa por suyo sea realmente el producto del pacto. En realidad la maternidad es la base no sólo de la filiación legítima, sino también de la filiación natural. De la definición apuntada se desprende que la maternidad es un hecho material que se descompone a su vez en dos: en el hecho del parto, esto es, que una mujer dio a luz un hijo; y en la identidad del parto, es decir, que el hijo que pasa por hijo de tal mujer sea realmente el producto del parto. En consecuencia, se acreditará la maternidad probando estos hechos. Sin embargo, la partida de nacimiento es suficiente prueba de maternidad y a aquel que pretenda destruirla deberá acreditar la no existencia de los hechos que la constituyen; en otras palabras: le será necesario probar la falsedad del parto o la no identidad del hijo...". Se pensaba que no había razones para dudar de la veracidad de la madre; agrega FueYo, Fernando, Derecho Civil VI: Derecho de Familia, T. II, Universo, Santiago, 1959, № 707, p. 311, que "se da por sentado -presuntivamenteque la cónyuge es sincera al afirmar que ha ocurrido un parto y que la criatura es precisamente la que ella exhibe como suya". Rossel, Enrique, Derecho de Familia, $7^{a}$ Edición, Editorial Jurídica de Chile, Santiago, 1993, № 309, p. 211, se desembarazaba del asunto señalando que "la maternidad es un hecho notorio, susceptible de prueba directa, de manera que su establecimiento o su impugnación son
} 
esta determinación de la maternidad. Así, Gisella López Rivera estima que la norma ha de ser considerada un progreso sustentado por la tutela del derecho a la identidad del hijo: "Considero que en este aspecto, nuestra legislación logra un gran avance, ya que anteriormente no existía ninguna norma que determinara la filiación de la madre respecto del hijo. Hoy, se contempla una modalidad que opera ipso iure por el hecho del parto, cuando consten en las partidas del Registro Civil ambas identidades"10. Paulina Veloso da cuenta de que en otras legislaciones como la española se toma en cuenta la voluntad de la madre y se permite que la maternidad no quede determinada si ella prefiere mantener el anonimato. Justifica la opción del legislador chileno por la coherencia que la norma tiene con todo el texto legal de la reforma que otorga prioridad a los intereses del hijo sobre el de sus padres: "En nuestro caso, siguiendo la lógica del texto de hacer primar los intereses de los hijos por sobre los de sus padres biológicos, la ley impuso perentoriamente la maternidad, una vez que se comprueben los elementos fácticos que la ley establece, no siendo la voluntad de la madre un aspecto que la ley haya considerado"11. Maricruz Gómez de la Torre apunta que la reforma tiene efectos amplios, ya que "hoy día la mayoría de las mujeres chilenas concurren a los hospitales a dar a luz a los hijos. Por tanto, los niños que nacen en estas condiciones tienen determinada la maternidad"12.

\section{Determinación de la maternidad en la legislación latinoamericana}

En algunas legislaciones latinoamericanas se mantiene la idea de que la maternidad matrimonial se determina por el parto (cosa que asumen implícitamente ya que les preocupa sólo configurar la presunción de paternidad de marido), y la maternidad extramatrimonial requiere reconocimiento o declaración judicial. De este modo, el Código Civil del Perú (arts. 388 y 409). En el caso del Ecuador el Código Civil también permite la determinación por reconocimiento

cuestiones de mecánica jurídica más bien que de principios". Algo parecido afirmaba MEZA BARROS, Ramón, Manual de Derecho de Familia, T. II, 2 a Edición, Editorial Jurídica de Chile, Santiago, 1979, n. 743, p. 480: "La maternidad es un hecho ostensible y por ello fácilmente demostrable". Curiosamente ninguno de estos autores se hacía cargo de la incongruencia que significaba facilitar de este modo la prueba de la maternidad legítima e imponer al hijo, a falta de reconocimiento, un juicio para probar la maternidad ilegítima.

${ }^{10}$ López, Gisella, Nuevo estatuto de filiación y los derechos esenciales, Conosur, Santiago, 2001, p. 140. La autora incluso critica la exigencia formulada por la Ley de Registro Civil de que se acredite la identidad de la madre y del hijo con el comprobante de parto emanado de un médico, lo que no podría ser aplicado en casos como los de una mujer inmigrante indocumentada.

${ }^{11}$ Veloso, Paulina, en Schmidt, Claudia; Veloso, Paulina, La filiación en el Nuevo Derecho de Familia, ConoSur, Santiago, 2001, p. 96.

${ }^{12}$ Gómez de la Torre, Maricruz, El sistema filiativo chileno, Editorial Jurídica de Chile, Santiago, 2007, p. 63. 
de la madre (art. 261) y por sentencia judicial (272), pero se mantiene la restricción del original texto del Código chileno (fuente de Código ecuatoriano) respecto de la mujer casada, sólo que no es absoluta sino que se la condiciona a que el marido haya obtenido previamente sentencia que declare que él no es el padre (art. 273). El Código Civil de Paraguay igualmente admite las dos formas: reconocimiento (art. 232) y sentencia judicial en juicio de filiación, pero es más restrictivo respecto de la investigación de la maternidad ya que la prohíbe si se trata de mujer casada, salvo que el hijo hubiere nacido antes del matrimonio (art. 234 inc. $3^{\circ}$ ). Algo similar sucede en Uruguay, donde el Código Civil, sólo parcialmente modificado, mantiene como formas de determinación de la maternidad extramatrimonial el reconocimiento y el juicio de investigación, pero éste lo veda absolutamente tratándose de mujer casada (art. 242) ${ }^{13}$. Semejante es el modelo asumido por el Código de Nicaragua: se permite el reconocimiento de la maternidad ilegítima (art. 221) y la investigación de ella en juicio por cualquier medio ordinario (art. 226), pero la acción no procede cuando se trata de atribuir un hijo a una mujer casada (art. 227). El Código Civil para el Distrito Federal de México señala que la filiación extramatrimonial puede determinarse por reconocimiento en el acto de inscripción del hijo en el Registro Civil (art. 60) o en instrumento posterior (art. 78), por la posesión de estado o por sentencia en juicio de filiación donde pueden presentarse todos los medios de prueba que la ley autoriza, "incluyendo aquellas que el avance de los conocimientos científicos ofrecen" (art. 341).

En cambio, en otras legislaciones se agrega al reconocimiento y la sentencia judicial, la posibilidad de que la madre sea determinada por el parto de manera automática. Es lo que sucede en Colombia en virtud del art. $1^{\circ}$ de la Ley $N^{\circ}$ 0045, de 1936, según el cual el hijo de padres que al tiempo de la concepción no estaban casados entre sí, es hijo natural, cuando ha sido reconocido o declarado tal con arreglo a lo dispuesto en esta ley; y se agrega: "También se tendrá esta calidad respecto de la madre soltera o viuda por el solo hecho del nacimiento". El Código Civil venezolano establece igualmente que "la filiación materna resulta del nacimiento, y se prueba con el acto de la declaración de nacimiento inscrita en los libros del Registro Civil, con identificación de la madre" (art. 197). A falta de esta forma, la maternidad puede determinarse por reconocimiento, posesión de estado o en juicio en el que se reciben todo tipo de pruebas (arts. 198 y 199).

Más completa es la regulación que la Ley № 24.540, de 1995, hizo en el art. 242 del Código Civil de Argentina, donde se señala que "la maternidad quedará establecida aun sin reconocimiento expreso, por la prueba del nacimiento y la identidad del nacido". Se dispone que la inscripción debe realizarse

${ }^{13}$ El artículo es muy similar al art. 289 del original Código Civil chileno. 
a petición de cualquiera que presente un certificado del médico u obstétrica que haya atendido el parto de la mujer a quien se atribuye la maternidad del hijo y la ficha de identificación del recién nacido ${ }^{14}$. Pero se exige que la mujer sea notificada: "Esta inscripción deberá serle notificada a la madre salvo su reconocimiento expreso, o que quien hubiese denunciado el nacimiento fuere el marido"15. En caso de que esta regla no pueda aplicarse, la filiación materna puede determinarse por reconocimiento (art. 248 inc. $2^{\circ}$ ) o por sentencia judicial en juicio de reclamación de estado (art. 254).

Finalmente, puede mencionarse el Código Civil de Brasil de 2002, aunque en esto mantiene con modificaciones menores, la norma del art. 356 del Código de 1916. Se contempla, ahora en el art. 1608 del nuevo Código, que cuando la maternidad consta del "termo do nascimento do filho", la madre sólo podrá impugnarla probando falsedad del término o de las declaraciones contenidas en él.

Como vemos, en ninguna de las legislaciones reseñadas se encuentra la figura de una inscripción del hijo con garantía de anonimato de la madre, poniéndola incluso a resguardo de una posterior acción de reclamación de estado del hijo. Cuando más, se le permite de hecho no reconocer al hijo (aunque algunas legislaciones como la mexicana declaran que es un deber de los padres el reconocer a sus hijos). En otros casos, de modo simular a lo que sucede con la ley chilena, se impone a la madre la determinación de la maternidad por su identificación en el trámite de inscripción de nacimiento del hijo, sin que sea necesaria su intervención. Sólo la legislación argentina prevé la notificación de la mujer que no haya reconocido (salvo que el denunciante del nacimiento sea el marido de la madre).

\section{Inconveniencia de resguardar el anonimato de la madre soltera: primacía de la verdad biológica}

Como ya lo anuncia el título de este parágrafo, estimamos que, al menos en el contexto sociocultural chileno y latinoamericano, debe prevalecer en el caso en conflicto que se analiza el interés y derecho del hijo a conocer la identidad de su madre.

\footnotetext{
${ }^{14}$ La Ley $N^{\circ} 24.540$, de 1995, establece una completa regulación sobre la forma de acreditar la maternidad, que se debe aplicar en todos los establecimientos médicos y señala que todos los datos deben consignarse en una ficha única, numerada por el Registro Nacional de las Personas. Esta ficha es indispensable para proceder a la determinación de la maternidad por el hecho del parto.

${ }^{15}$ Se trata de una notificación administrativa de mera información. Es decir, la mujer notificada no puede oponerse a la determinación legal de la maternidad, que opera automáticamente por la sola inscripción del nacimiento. Para desconocer al hijo, debe intentar la acción judicial de impugnación. Cfr. MazzINGHI, Jorge Adolfo, Tratado de Derecho de Familia, T. IV, 4ª Edición, La ley, Buenos Aires, 2006, §656, p. 10.
} 
Para llegar a esta conclusión es necesario determinar cómo juegan los conceptos de interés y derecho en los conflictos entre personas diversas y, en este caso, entre la madre y el hijo.

Si consideramos la cuestión sólo desde el punto de vista de intereses en colisión, nos parece que la solución se encuentra de parte del interés del hijo. En efecto, si pensamos que la madre puede tener un legítimo interés en no revelar su identidad al momento del parto o en la inscripción de nacimiento del hijo, éste debe ser contrastado con el interés del niño de conocer a su progenitora. La ponderación de estos dos intereses debería llegar a la conclusión de que tiene mayor peso o solidez jurídica el interés del niño o favor filii, puesto que la Convención de Derechos del Niño lo califica de "superior" o "mejor", ordenando que se atienda a él como "consideración primordial".

Con mayor razón deberemos arribar al mismo resultado, si enfrentamos el interés de la madre ahora con lo que es el derecho a la identidad del hijo. Resulta manifiesto que un mero interés, en este caso de la mujer que ha dado a luz, no puede imponerse por sobre un derecho fundamental o de la personalidad, garantizado a toda persona. Lo mismo sucederá si sostenemos que si el hijo es mayor de edad ya no debe beneficiarse del estándar del interés superior del niño. En este caso, el derecho a la identidad lo amparará para vencer la pretensión de anonimato de la madre que se sustente en meros intereses de ésta, por muy legítimos que sean.

Se podría argüir que la madre no cuenta sólo con meros intereses para proteger su pretensión sino también con un verdadero y auténtico derecho, también fundamental o de la personalidad, cual sería el derecho a la intimidad o al respeto de su vida privada. Digamos, primeramente, que parece muy dudoso que el derecho a la vida privada personal o familiar pueda incluir el ocultamiento de la identidad de un padre respecto del hijo que desea conocerle. Las relaciones familiares y el estado civil son materias de interés público y que no pueden quedar en la reserva de la intimidad. De hecho, existe un Registro público para dar cuenta de estos vínculos de parentesco. Otra cosa es que las circunstancias de la procreación o nacimiento queden amparadas en la esfera de la intimidad, pero esto no incluye la mera relación paterno-materno-filial ni la identidad de sus sujetos. Si fuera así todo demandado en juicio de investigación de la paternidad opondría a la petición de indagación judicial el respeto del derecho a la vida privada.

No obstante, asumiendo sólo para efectos dialécticos que la madre podría ampararse en un derecho fundamental para lograr tutela de su deseo de permanecer en anonimato, la cuestión tampoco podría resolverse a su favor. Ciertamente, en tal caso podría considerarse que el interés del hijo o favor filii, incluso en su consideración superior o primordial, no podría oponerse con éxito a un auténtico derecho que se opone a su realización. Pero no sucede lo 
mismo con el derecho a la identidad del hijo, ya sea menor o mayor de edad. En tal caso, la colisión se daría entre derechos fundamentales, a la intimidad por parte de la madre, y a la identidad por parte del hijo. Nos parece que si así fuera los tribunales deberían ahora decidir por el derecho del hijo, y sostener que la intimidad de la madre se ve limitada por el derecho del hijo a conocer sus raíces biológicas. Esto al menos por dos razones: primero, porque pareciera más esencial para el desarrollo de la personalidad y, por tanto, con mayor jerarquía jurídica, el derecho a la identidad que el derecho a la intimidad personal o familiar (lo cual han reconocido las leyes al instaurar el principio de libre investigación de la paternidad como regla general). En segundo lugar, por cuanto el derecho a la identidad viene a ser reforzado en este caso por la concurrencia del interés superior del hijo o favor filii que aporta un elemento de juicio importante a la hora de ponderar la fuerza de ambos sustentos jurídicos ${ }^{16}$.

En todos los casos anteriores, se sustenta que el derecho a la identidad es un derecho fundamental que le asiste a toda persona y que, tratándose del niño, contiene el derecho a conocer a sus padres, tal como lo garantiza la Convención de Derechos del Niño. Para relativizar el reconocimiento internacional de este derecho se sostiene que el precepto de la Convención en forma cauta declara que el niño tendrá derecho "en la medida de lo posible" a conocer a sus padres. Pero la frase no puede prestarse para una interpretación tan elástica que termine por privar de todo sentido el reconocimiento solemne de un derecho. Se olvida que ella se predica conjuntamente del derecho a conocer a sus padres como del derecho a ser cuidado por ellos. Se entiende, en consecuencia, que el matiz tiene una connotación predominantemente fáctica. No siempre será posible, en la realidad de los hechos, que el niño sea cuidado por sus padres (por ejemplo, si han muerto) o que sean conocidos (si de hecho han ocultado su identidad). En este caso, el Estado no podría garantizar el ejercicio de este derecho pues no le es posible por acciones positivas darle cumplida realidad. Pero otra cosa es que el Estado ponga obstáculos legales o administrativos al ejercicio de un derecho que podría fácticamente

\footnotetext{
${ }^{16}$ La limitación que puede hacerse en virtud de la muerte del supuesto padre o madre, contemplada entre nosotros en el art. 206 del Código Civil, nos parece que puede ser justificada puesto que ya no se trata del derecho a la intimidad del mismo padre o madre sino de sus familiares y dado que el derecho a la identidad en estos casos suele estar contaminado con intereses patrimoniales de participación en la herencia del fallecido. Cfr. CORRAL TALCIANI, Hernán, “¿Puede interponerse la acción de reclamación de filiación en contra de los herederos del supuesto padre fallecido?", Gaceta Jurídica № 347, 2009, pp. 7-22. El Tribunal Constitucional, sin embargo, ha estimado que la prescripción adquisitiva es suficiente garantía de estabilidad para los herederos del presunto padre, por lo que declaró inaplicable por inconstitucionalidad el art. 206 del Código Civil (Sentencia de 21 de septiembre de 2009, Rol № 1340-9).
} 
obtener cumplimiento. Tales medidas no quedan autorizadas por la frase "en la medida de lo posible", pues es el mismo Estado el que está haciendo imposible algo que de suyo no lo es.

Finalmente, queda analizar la cuestión del encuentro entre dos intereses o derechos del mismo hijo, pero que apuntan en direcciones opuestas. Se trataría del derecho a la vida, por una parte, y del derecho a la identidad por otra; o de dos formulaciones del interés superior del niño o favor filii: el interés de venir al mundo y no ser abortado, asesinado en los primeros meses de existencia o abandonado en una situación de peligro para su vida, y el interés de conocer a su madre biológica.

La cuestión se pone en estos términos: si a la madre se le garantiza el anonimato ella puede ser disuadida de librarse de un niño producto de una concepción no deseada y entregarlo a una custodia segura de terceros o a la adopción. En cambio, si se le impone la maternidad legal (por la determinación por vía del parto, como sucede en Chile y otras naciones latinoamericanas) o se la deja sujeta a una eventual acción futura de investigación de la maternidad, ella se verá muy presionada por el medio para que termine deshaciéndose de su hijo por aborto, infanticidio o abandono. En estas condiciones, parece que lo más importante para el hijo, y para la sociedad, es la protección de su vida (en gestación o de recién nacido) y no su interés en conocer quién ha sido su progenitora. El anonimato de la madre debería serle garantizado no por tutelar un interés o derecho de ella misma, sino por el mismo bienestar e interés del hijo.

Esta argumentación nos resulta difícil de aceptar porque podría prestarse para configurar un verdadero chantaje legal: o me aseguras la impunidad de la maternidad, no sólo en los deberes y responsabilidades del vínculo parental sino incluso en la mera identificación, o no vivirás para contarlo... La identidad por la vida. Resulta muy duro negarle a un hijo el derecho a conocer su identidad y la de sus padres biológicos a pretexto de que de esa forma fue protegido contra las amenazas contra su vida de esos mismos padres biológicos. Pareciera una forma sutil de aprovechamiento del propio dolo.

Enfrentando la cuestión desde el punto de vista dogmático, no parece haber propia colisión entre derechos e intereses del mismo hijo, porque no existe una amenaza directa, cierta e inminente a su vida que sea claramente el resultado de garantizarle su derecho a la identidad y a la revelación de la identidad de su madre biológica. ¿Por qué se piensa que por el simple expediente de no declarar al hijo como suyo la madre no va a proceder al aborto si este era su deseo? ¿Se ha demostrado que son menos los abortos en los países que acogen esta figura que aquellos que tutelan la identidad del menor? ¿Existe realmente una relación de causa a efecto entre anonimato de la madre y preservación de la vida del hijo y de su integridad física? Por cierto, se puede conjeturar, manejar sensaciones 
subjetivas de lo que es el ambiente actual, de la presión social sobre las mujeres gestantes, pero sobre datos tan febles no pueden erigirse políticas públicas o diseños normativos que terminen por lesionar un derecho fundamental tan gravitante en el desarrollo de la persona como el de la identidad ${ }^{17}$.

Si la cuestión fuera tan simple en el sentido de que el anonimato del progenitor preserva la vida del hijo, no vemos razones para no extender este predicamento también al padre. En muchas ocasiones, es más el progenitor masculino el que estará interesado en que el niño no nazca o no sobreviva, para efecto de librarse de sus deberes y responsabilidades que la ley le impone. Es el padre el que en ocasiones sugiere y presiona a la madre para que termine por deshacerse de un hijo no querido. Pues bien, ¿no podría decirse que también habría que ofrecerle una garantía de anonimato para que así se sienta disuadido de presionar por el aborto de la criatura o de asesinarla una vez nacida? Si así fuera todos los esfuerzos realizados en las últimas décadas para lograr la investigación de la paternidad y tutelar el derecho del hijo a conocer a sus padres, se vendría abajo de una sola sentada.

Por otra parte, es bueno pensar si existen medios alternativos que permitan hacer frente a los problemas que puede tener una madre para dar a luz y hacerse cargo de su hijo sin necesidad de suprimir un derecho fundamental del hijo como el de conocer su origen biológico. Por cierto, centros de acogida de madres solteras e instituciones de ayuda a la maternidad deberían tener un gran papel en esta labor. En última instancia, debería ofrecerse a la madre que no puede quedarse con su hijo que lo entregue voluntariamente en adopción. En ese caso, su nombre no se inscribirá como madre del hijo o se suprimirá del Registro, con lo cual ella queda suficientemente protegida y descargada de la presión que la agobia en esos momentos. Pero el derecho a la identidad del hijo no deberá ser cercenado, pues debe garantizarse al adoptado que, una vez cumplida la mayoría de edad, si él así lo quiere, puede acceder al proceso de

\footnotetext{
${ }^{17}$ En este sentido, el voto disidente firmado por siete jueces del Tribunal Europeo de Derechos Humanos en el juicio "Odièvre c. France" (Requête No 42326/98, sentencia de 13 de febrero de 2003) rechaza el argumento por el cual los jueces de la mayoría (10) fallaron que la legislación francesa no viola la Convención Europea de Derechos Humanos en cuanto garantiza el anonimato de la madre para así salvaguardar la vida e integridad del hijo que podría ser puesta en peligro por un aborto o exposición. Los disidentes señalan a nuestro juicio con acierto: "Sobre el terreno del interés general, la Corte invoca, especialmente, la necesidad de evitar los abortos clandestinos... En primer lugar, es necesario mencionar que el riesgo del aumento de los abortos, incluso de los infanticidios, en la hipótesis en que el parto bajo ' $X$ ' fuera suprimido, no ha sido sostenido por datos serios en el estado actual de las cosas. Además, ello implicaría evaluar este riesgo a la luz de la situación que existe en los países que no conocen el parto bajo ' $X$ '. Pues no ha sido establecido, sobre la base de datos estadísticos específicamente, que haya una elevación del número de abortos ni de infanticidios en la mayoría de los países de Europa que no poseen una legislación del tipo de aquella que existe en Francia" (la traducción es nuestra).
} 
adopción y conocer la identidad de su madre biológica. Esto no significa que pueda rechazar a sus padres adoptivos y reclamar la determinación legal de la filiación materna. La adopción seguirá teniendo vigencia y sus padres serán los adoptivos. La progenitora biológica quedará a cubierto de toda reclamación de derechos por parte del hijo, ya que éste lo único que puede pretender (y lo que interesa a efectos de tutela de la identidad) es la identificación personal de quien lo dio a luz. Nada más, y nada menos.

Finalmente, la opción que garantiza a la madre el anonimato a cambio de que abandone oficialmente al hijo presenta inconvenientes de carácter práctico que provienen de la total ausencia de la consulta al deseo y voluntad del padre. Así lo demuestra el Ilamado caso "Benjamín" ventilado ante los tribunales franceses: el niño Benjamín fue entregado por su madre bajo la figura del "accouchement sous X" al pupilaje del Estado y luego solicitado en adopción por un matrimonio, al que se confió su cuidado personal. Cuando se estaba por dictar la sentencia definitiva el padre biológico reclamó la restitución del niño aduciendo un reconocimiento otorgado mientras aquél estaba en el vientre materno. Dos Cortes de Apelación por distintas razones negaron el derecho del padre biológico a reclamar a su hijo y confirmaron la adopción. No obstante, la Corte de Casación anuló las sentencias dando valor al reconocimiento del padre y ordenando la reapertura del proceso adoptivo, con la intervención del padre. Finalmente, en una especie de decisión concordada, la Corte de Reims otorgó a los padres adoptivos no la adopción plena pero sí la simple, que permite la fijación de un régimen de relaciones con un tercero, que en este caso será el padre biológico ${ }^{18}$. Todo un entuerto, que con seguridad no ha beneficiado al menor, por el privilegio otorgado a la mujer de ocultar su identidad materna ${ }^{19}$.

\footnotetext{
${ }^{18}$ La sentencia de la Corte de Casación (Civ. $1^{\text {a }}, 7$ de abril de 2006), aparece comentada en la Revue Trimestrielle de Droit Civil 2006, 2, pp. 273-275. La Corte invocó la Convención de Derechos del Niño, art. 7, estimando que es aplicable directamente para otorgar al hijo, desde su nacimiento y en la medida de lo posible, el derecho a conocer a sus padres. La sentencia de la Corte de Reims (C. Reims, 12 de diciembre de 2006, Defrénois, 2007. 795), es comentada en la misma Revue 2007, 3, p. 558.

${ }^{19}$ El voto disidente del asunto "Odièvre c. France" pone de relieve el desequilibrio que provoca el darle una especie de derecho de veto unilateral e incausado a la madre, respecto del padre o de los hermanos del hijo que resultará privado de su filiación. Señalan los jueces que "la madre dispone así de un derecho puramente discrecional de poner en el mundo un hijo en suspenso y condenarlo, para toda su vida, a la ignorancia. El 'derecho de veto' puro y simple reconocido a la madre entraña por efecto que los derechos del hijo, reconocidos en la economía general de la Convención [Europea de Derechos Humanos] sean enteramente descuidados, olvidados. Además, la madre puede también, de la misma manera, paralizar los derechos de terceros, especialmente aquellos del padre biológico y de los hermanos y hermanas, que pueden también ser privados de los derechos garantizados por el artículo 8 de la Convención".
} 


\section{El contexto sociocultural chileno y latinoamericano}

La solución que se propicia de un modo general en el apartado anterior, debe ser sostenida con mayor énfasis si se atiende a la realidad social y cultural de Chile y en general de Latinoamérica. Esto, por dos elementos que marcan una diferencia con la realidad centroeuropea.

Lo primero es la mayor valoración jurídica y social de la vida e integridad del nasciturus. Desde sus comienzos, nuestros Códigos civiles han tutelado la vida naciente como la de un ser humano apreciado y apreciable. El Código Civil chileno (1857) contiene la declaración de que "la ley protege la vida del que está por nacer" (art. 75 inc. $1^{\circ}$ ), (hoy incorporada a la misma Constitución Política: art. $19 \mathrm{~N}^{\circ} 1$, como parte de la normativa destinada a proteger el derecho a la vida). El Código Civil argentino lo considera "persona por nacer" (art. 63 y ss.).

No resulta extraño que el aborto sea considerado y sancionado como un delito penal.

Aquí se contempla ya un disuasivo fuerte y real para que las madres embarazadas no recurran a este ominoso expediente y, lo que es más eficaz, para que los terceros (el padre incluido) no las presionen para que consientan en un aborto que necesariamente será clandestino e ilegal. Las tesis pro legalización del aborto sostienen que la criminalización de éste es una mala política porque incentiva la clandestinidad y los peligros para la mujer, pero las cifras ponen de manifiesto que la legalización del aborto no produce una disminución del número de ellos, lo que es lógico puesto que de alguna manera la sociedad invita a estas mujeres angustiadas a "resolver" su problema eliminando al niño. La mujer queda expuesta a todo tipo de presiones para que haga uso de un derecho que la misma ley le acuerda en vez de "molestar" a todos con la llegada de un hijo.

Un segundo punto que marca diferencias entre el contexto latinoamericano y europeo es la valoración de la maternidad. En nuestras sociedades latinoamericanas, formadas como producto del mestizaje y muchas veces de uniones no matrimoniales entre conquistadores e indígenas, la figura de la madre tiene un aprecio por sí sola, con independencia de si está o no casada. La cuestión de la "deshonra" de la mujer por quedar esperando un niño fuera de matrimonio es mucho menos intensa, sobre todo en los sectores populares, que la que parece existir todavía (a pesar de su supuesto y proclamado liberalismo) en las sociedades europeas. Piénsese que hasta Bernardo O'Higgins, el prócer de la independencia de Chile y homenajeado como "Padre de la Patria", era hijo de mujer soltera (Isabel Riquelme) y nunca fue reconocido por su padre (el irlandés al servicio de España Ambrosio O'Higgins, quien fue gobernador de Chile y más 
tarde Virrey del Perú $)^{20}$. La maternidad es siempre bienvenida. La figura de la madre es central en el imaginario social de Latinoamérica. Es la madre la que normalmente saca adelante a su marido y a los hijos, incluso la que mantiene sola el hogar cuando ha sido abandonada por el padre de sus hijos. A la madre se le perdona todo, se la protege y se la estima. El peor insulto que puede dirigirse a una persona en Chile se denomina "sacarle a uno su madre". Lo peor que le puede pasar a una persona, no es tanto que su padre no lo quiera reconocer, sino que no lo reconozca su madre. Por eso mismo el recurso al aborto resulta trágico y hasta cierto punto de vista una negación de la misma mujer que, al matar a su hijo, se destruye también a sí misma.

En este contexto, el proponer que se garantice el anonimato de la madre a cambio de que ésta respete la vida del niño por librarse de la "deshonra" que implicaría tenerlo, carece de justificación, ya no solamente desde el punto de vista dogmático sino también sociológico.

\section{Sobre el anonimato del donante de Gametos en las téCnicas de REPRODUCCIÓN HUMANA ASISTIDA}

Por necesaria coherencia argumental, debemos concluir que también el derecho a la identidad, la protección del interés superior del niño y el principio de la verdad biológica del actual Derecho de Filiación, abonan la tesis de que el hijo que ha sido el resultado de la aplicación de técnicas de reproducción artificial o asistida con la intervención de aportantes de gametos masculinos o femeninos (las Ilamadas "técnicas heterólogas") tiene la facultad de conocer al menos la identidad de quienes han sido sus progenitores genéticos.

Nuevamente, el interés que pudiera existir en el aportante de mantener su anonimato o el de los padres afectivos de que no perturbe la estabilidad de la relación legal establecida con el hijo, no pueden pesar más que el derecho a la identidad de la persona así concebida.

Coincidimos con el profesor Durán, que resulta paradójico y discriminatorio que en ámbitos jurídicos como el de España, el Tribunal Constitucional haya mantenido la legitimidad del anonimato legal del aportante de gametos (ordinariamente de sexo masculino) en las técnicas de reproducción asistida y, en cambio, ponga en entredicho la norma que garantiza el anonimato de la madre en caso de hijo nacido naturalmente pero en peligro de aborto o abandono. ¿Por qué en este caso debe prevalecer el derecho a la identidad, el favor filii y el principio de verdad biológica y no en el primero? A nuestro juicio, ambos

\footnotetext{
${ }^{20}$ No fue reconocido oficialmente, pero su padre cuidó, a través de terceros, de que tuviera una esmerada educación, incluso en Inglaterra, donde conoció a Francisco de Miranda.
} 
supuestos deben tener soluciones coincidentes; o bien se niega en ambos el derecho a la identidad y se preserva el anonimato o, como nosotros mantenemos, se da cumplimiento a las exigencias que impone el derecho a la identidad, apoyado por el interés superior del niño y el principio de verdad biológica de la filiación, otorgando al menos al hijo, alcanzada la plena capacidad, el derecho a conocer la identidad del progenitor genético ${ }^{21}$.

En Chile, la Ley № 19.585 que reformó la regulación de la filiación y estableció el principio de la verdad biológica incorporó una norma: el art. 182 del Código Civil, sobre la filiación del hijo concebido a través de técnicas de reproducción asistida que resulta problemática de interpretar porque, a primera vista, contradice el referido principio y cercena, en caso de intervención de terceros que aportan gametos, el derecho del hijo concebido a conocer la paternidad o maternidad biológicas. Señala la norma textualmente: "El padre y la madre del hijo concebido mediante la aplicación de técnicas de reproducción humana asistida son el hombre y la mujer que se sometieron a ellas. No podrá impugnarse la filiación determinada de acuerdo a la regla precedente, ni reclamarse una distinta".

Con una terminología y redacción poco satisfactoria, la ley parece determinar legalmente la filiación del hijo concebido mediante técnicas heterólogas (con aportación de gametos ajenos) atribuyéndola al varón y la mujer que consintieron en la realización de esa técnica: "se sometieron a ellas". La norma no tendría sentido si se refiriera a técnicas homólogas o heterólogas sin consentimiento expreso y específico. La cuestión que nos preocupa se centra en la firmeza que la ley atribuye a la filiación así determinada. Ella no puede ser contradicha por el ejercicio de una acción de impugnación de la paternidad o maternidad que intente demostrar que no existe la relación biológica entre el padre formal y el hijo nacido por aplicación de la tecnología. Tampoco puede ejercerse una acción de reclamación de una filiación incompatible con la determinada (la que debería ir aparejada de una necesaria acción de impugnación) que intentara demostrar el vínculo biológico que liga al hijo con el aportante de los gametos con los que se le concibió.

No parece haber duda que el precepto veda el ejercicio de la acción de impugnación por parte del padre formal que pretenda demostrar que el hijo

\footnotetext{
${ }^{21}$ Desde hace ya varios años hemos sustentado el derecho del hijo a conocer la identidad del progenitor biológico no sólo en los casos de investigación de la paternidad o maternidad extramatrimonial, sino también en los de filiación adoptiva y en la filiación determinada por la aplicación de una técnica de reproducción asistida con intervención de terceros aportantes de gametos. Al respecto puede verse el capítulo sexto titulado "Libre investigación de la paternidad o maternidad y derecho a conocer la identidad del progenitor" de nuestro libro CoRRAL, Hernán, Familia y Derecho. Estudios sobre la realidad jurídica de la Familia, Universidad de los Andes, Santiago de Chile, 1994, pp. 165-194. El trabajo es anterior a la reforma del sistema filiativo chileno realizada por la Ley № 19.585, de 1998.
} 
concebido con gametos ajenos no es en realidad (biológicamente) hijo suyo. Tampoco suscita controversia la conclusión de que la norma impide al tercero aportante de gametos el ejercicio de la acción de reclamación de la paternidad o maternidad biológica respecto de hijo concebido de esta forma, así como la necesaria acción de impugnación de la filiación del padre o madre formales (no biológicos).

Pero sí es dudoso el alcance de la exclusión de las acciones de reclamación o impugnación por parte del hijo, sobre todo si ha llegado a la mayoría de edad y es plenamente capaz.

El tema ha sido discutido por la doctrina chilena que ha examinado la reforma de la filiación. René Abeliuk se muestra partidario de una interpretación literal del texto y de negar la acción de impugnación o reclamación incluso al hijo, aunque ello pueda ser criticable de lege ferenda: "En nuestro concepto, no cabe duda, que la disposición [del inciso $2^{\circ}$ del art. 182] se aplica tanto al tercero que proporcionó los gametos como al hijo fruto de esta reproducción asistida. Que la solución pueda ser criticable no cabe duda, pero ello no puede permitir torcer su claro sentido"22. En cambio, Maricruz Gómez de la Torre parece sostener que es posible la acción de investigación de la paternidad biológica: "Si bien estoy de acuerdo con las limitaciones establecidas, considero que el hijo que nace producto de la aplicación de una TRA [Técnica de Reproducción Asistida] con donante debe tener la posibilidad de saber que fue concebido por este procedimiento y quién es su progenitor biológico, cuando alcance la mayoría de edad..."23. Por su parte, Paulina Veloso sostiene que "es discutible la solución de negar el derecho del menor a conocer su origen biológico, es decir, negarle su derecho a la identidad"24. Algunos autores han sugerido que al prohibir la investigación de la paternidad biológica la norma podría ser tachada de inconstitucional y contraria a los tratados internacionales, con particular mención de la Convención de Derechos del $\mathrm{Niño}^{25}$.

Por nuestra parte, preferimos una interpretación de la norma que, superando el mero tenor literal (que tampoco es categórico), permita entenderla vigente de un moco congruente con la normativa constitucional e internacional. Aunque

\footnotetext{
${ }^{22}$ Aвeцıuk, René, La filiación y sus efectos, T. I, Editorial Jurídica de Chile, Santiago de Chile, 2000, p. 121. Tampoco le parece clara la inconstitucionalidad o contrariedad con los tratados internacionales de la norma ya que las legislaciones extranjeras dan distintas soluciones al problema del anonimato del aportante de gametos.

${ }^{23}$ Gómez, El sistema, cit. nota n. 12, p. 126.

${ }^{24}$ Veloso en Schmidt; Veloso, La filiación, cit. nota n. 11, p. 127.

${ }^{25}$ Así, Peñallillo, Daniel en VV.AA., Modificaciones al Código Civil en materia de filiación y sucesión por causa de muerte, Universidad de Concepción, Concepción, 1999, p. 30; CouRT, Eduardo, Nueva Ley de Filiación, ConoSur, Santiago, 1999, p. 103, nt. 220.
} 
la letra del precepto no parece hacer distinciones, nos inclinamos a pensar que una interpretación sistemática y a la luz de los principios constitucionales e internacionales que rigen la materia, conduce a sostener que el precepto sólo se aplica a los padres biológicos y formales pero no al hijo, quien sigue gozando de la acción de reclamación (para demandar el establecimiento de la verdadera filiación respecto del progenitor biológico, esto es, el aportante de gametos) y de la acción de impugnación que necesariamente deberá intentar para dejar sin efecto la filiación formal. Se trata del ejercicio simultáneo de las acciones de reclamación e impugnación a que se refiere el art. 208 del Código Civil.

Para sustentar esta posición nos apoyamos en los siguientes argumentos:

$1^{\circ} \mathrm{El}$ art. 182 no señala expresamente que el hijo queda impedido de ejercer las acciones de impugnación y de reclamación, ni tampoco garantiza el secreto o el anonimato del tercero aportante de gametos. Este silencio es muy significativo ya que en la época en la que se dictó la ley (1998) se conocía perfectamente que las legislaciones extranjeras que regulaban esta materia para evitar las acciones de filiación garantizaban expresamente el secreto del aportante de gametos.

$2^{\circ} \mathrm{El}$ art. 182 debe interpretarse con arreglo a los principios que inspiran la reforma uno de los cuales es el de preferencia de la verdad biológica, como queda reflejado en el art. 195 del Código Civil que señala: "La ley posibilita la investigación de la paternidad o maternidad, en la forma y con los medios previstos en los artículos que siguen". Agrega la norma que "el derecho de reclamar la filiación es imprescriptible e irrenunciable".

$3^{\circ}$ La norma debe interpretarse también en consonancia con el principio de interés superior del niño o favor filii que, como hemos visto con anterioridad, ha sido también recogido por la reforma de 1998.

$4^{\circ}$ Del mismo modo, ante la inexistencia de una prohibición expresa de descubrir el anonimato del aportante de gametos debe entenderse que existe el derecho a conocer a los padres, proclamado por la Convención de Derechos del Niño (art. 7) que, siendo un tratado ratificado por Chile, tiene fuerza de ley en el ámbito interno.

$5^{\circ}$ La historia del establecimiento del precepto ilustra que los legisladores, al redactar el inciso segundo del art. 182 del Código Civil que excluye las acciones de impugnación y reclamación, pensaron sólo en evitar el desconocimiento del hijo por parte del marido o varón que no aporta los gametos o la pretensión del tercero aportante de perturbar la estabilidad de la familia formada por los padres formales mediante la reclamación de su paternidad biológica. En ninguno de los debates y discusiones parlamentarias se mencionó que se pretendía consa- 
grar un anonimato o secreto del tercero en contra de la pretensión del hijo de establecer la verdad de su filiación ${ }^{26}$.

Debe señalarse que hay quienes piensan que si no se admite la acción de investigación de la paternidad como una acción de filiación, es posible construir, sobre la base de lo dispuesto en el art. 7 de la Convención de Derechos del Niño, una acción judicial autónoma y específica cuyo objeto no sería la indagación de la paternidad con la consiguiente atribución de las responsabilidades y deberes paternos, sino simplemente la verificación de la identidad del progenitor biológico. Se trataría nada más que de la satisfacción del interés y derecho del hijo a construir su propia identidad mediante el conocimiento de la persona determinada cuyos gametos permitieron que ella viniera al mundo con las singulares características que la identifican ${ }^{27}$.

\section{Conclusiones desde el Derecho chileno y latinoamericano}

De lo expuesto anteriormente, hemos de concluir que, a nuestro juicio, no hay razones que permitan, desde la perspectiva del contexto jurídico latinoamericano, justificar una limitación al principio de verdad biológica de la filiación, al interés superior del niño y a su derecho a la identidad, ya sea por la aprobación de una legislación que admita, como sucede en algunos países europeos, la reserva de la identidad de la madre que ha dado a luz un hijo no estando casada, ya sea por la interpretación de un precepto legal poco categórico como el art. 182 del Código Civil chileno que ampare el anonimato de la identidad del tercero aportante de gametos en una técnica de reproducción

${ }^{26}$ En otras ocasiones hemos argumentado en el mismo sentido: CORRAL, Hernán, "La filiación en las técnicas de reproducción humana asistida", Revista de Derecho, Universidad Católica del Norte, 2000, pp. 97 y ss., especialmente pp. 110 y 111; "Reproducción humana asistida y filiación: un análisis del nuevo artículo 182 del Código Civil", Cuadernos Jurídicos 2, 2000, pp. 169-177. En este último trabajo hacemos ver que además se excluyó en el Senado un inciso tercero que disponía que la donación de gametos no constituía parentesco, dándose como razón que no se quería anticipar pronunciamiento sobre la regulación de los distintos temas asociados a las técnicas, que debía corresponder a otro proyecto de ley, y en particular sobre la aceptación o prohibición del uso de gametos de donantes, "y el eventual derecho de la persona así concebida para conocer su progenitura biológica". Hasta la fecha el proyecto de ley que regulaba las técnicas no ha sido aprobado, por lo que es menester aplicar sobre el punto las reglas generales. Lo que está claro que es que los legisladores no quisieron que el artículo 182 implicara una garantía de secreto o anonimato del tercero aportante de gametos.

${ }^{27}$ Veloso en Schmidt; Veloso, La filiación, cit. nota n. 11, p. 127, nt. 122, señala que "puede sostenerse que el hijo, siendo mayor de edad, estaría habilitado para -invocando su derecho a la identidad-solicitar en Tribunales que se determine su origen biológico, con otros fines, distintos a la determinación de la paternidad o maternidad. Además de poder sustentarse en el Convención de Derechos del Niño y otros tratados, y en la propia Constitución Política, en cuanto contempla implícitamente el derecho a la identidad, podría argumentarse que, en todo caso, ello no vulnera el artículo 182, que contiene la hipótesis de reclamación o impugnación de la filiación, lo que no sería el objeto pedido en el ejercicio de este tipo de acción". 
humana asistida. Incluso más, si se le interpretara de esta forma podría dar lugar a una impugnación de inconstitucionalidad o de contrariedad con la Convención Americana de Derechos Humanos (Pacto de San José de Costa Rica).

Comprendemos el argumento expuesto para el ámbito europeo por el profesor Durán, y apoyado en la sentencia de la Corte Europea de Derechos Humanos que juzgó el caso "Odièvre", en el sentido de que el anonimato de la madre puede justificarse sobre la base del mismo interés del hijo, que se ve tutelado por permitirle nacer y ponerlo a salvo del peligro de que la madre atente contra él para librarse de las angustias y agobios de un embarazo no deseado. Pero pensamos que esta justificación no es suficiente en el contexto del derecho chileno y latinoamericano, donde se tutela penalmente la vida del concebido y se tiene un aprecio histórico a la figura materna que disminuye o atenúa las presiones a la madre soltera.

\section{BibLiOgRafía}

Aвelıuk, René, La filiación y sus efectos, Editorial Jurídica de Chile, Santiago de Chile, 2000.

CORRAL, Hernán, “¿Puede interponerse la acción de reclamación de filiación en contra de los herederos del supuesto padre fallecido?", Gaceta Jurídica No $347,2009$.

"La filiación en las técnicas de reproducción humana asistida", Revista de Derecho (Universidad Católica del Norte), 2000.

" "Reproducción humana asistida y filiación: un análisis del nuevo artículo 182 del Código Civil", Cuadernos Jurídicos (Universidad Central) 2, 2000 .

Familia y Derecho. Estudios sobre la realidad jurídica de la Familia, Universidad de los Andes, Santiago de Chile, 1994.

Court, Eduardo, Nueva Ley de Filiación, Conosur, Santiago, 1999.

EtcheberRY, Leonor; Veloso, Paulina, "Proposiciones relativas a una nueva normativa en ciertas materias de filiación", en Barros, Enrique (Coord.), Familia y personas, Editorial Jurídica de Chile, Santiago, 1991.

Fernández Sessarego, Carlos, Derecho a la identidad personal, Astrea, Buenos Aires, 1992.

Fuero, Fernando, Derecho Civil VI: Derecho de Familia, Universo, Santiago, 1959.

Gómez de LA Torre, Maricruz, El sistema filiativo chileno, Editorial Jurídica de Chile, Santiago, 2007.

Historia de la Ley No 19.585: Modifica el Código Civil y otros cuerpos legales en Materia de Filiación, D. Of. 26 de octubre de 1998, elaborado por la 
Biblioteca del Congreso Nacional y accesible en el sitio web de dicha Biblioteca. En: http://www.leychile.cl/Navegar?idNorma=126366\&buscar=1 9585 [visitado el 17/05/2010].

Lloveras, Nora, "La identidad personal: lo dinámico y lo estático en los derechos del niño", Derecho de Familia. Revista interdisciplinaria de doctrina y jurisprudencia 13, 1998.

LÓPEZ, Gisella, Nuevo estatuto de filiación y los derechos esenciales, ConoSur, Santiago, 2001.

Mazzınghi, Jorge Adolfo, Tratado de Derecho de Familia, 4a Edición, La Ley, Buenos Aires, 2006.

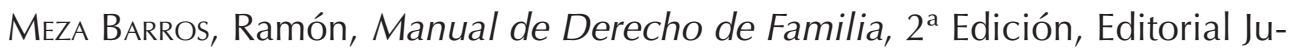
rídica de Chile, Santiago, 1979.

PeÑalılılo, Daniel, "Las categorías de filiación y la investigación de la paternidad", en VV.AA., Modificaciones al Código Civil en materia de filiación y sucesión por causa de muerte, Universidad de Concepción, Concepción, 1999.

Rossel, Enrique, Derecho de Familia, $7^{\text {a }}$ Edición, Editorial Jurídica de Chile, Santiago, 1993.

Schmidt, Claudia; Veloso, Paulina, La filiación en el Nuevo Derecho de Familia, Conosur, Santiago, 2001.

Somarriva, Manuel, Derecho de Familia, Nascimento, Santiago, 1963. 1955. Evolución del Código Civil chileno, Nascimento, Santiago, La filiación. Estudio doctrinal y de legislación comparada, Imprenta "El esfuerzo", Santiago, 1931. 
